\title{
Cancer incidence in Ghana, 2012: evidence from a population-based cancer registry
}

\author{
Dennis O Laryea ${ }^{1,2^{*}}$, Baffour Awuah ${ }^{2,3}$, Yaw A Amoako ${ }^{4}$, E Osei-Bonsu ${ }^{3}$, Joslin Dogbe ${ }^{5}$, Rita Larsen-Reindorf ${ }^{6}$, \\ Daniel Ansong ${ }^{7}$, Kwasi Yeboah-Awudzi ${ }^{8}$, Joseph K Oppong ${ }^{9}$, Thomas O Konney ${ }^{10}$, Kwame O Boadu ${ }^{11}$, \\ Samuel B Nguah ${ }^{5}$, Nicholas A Titiloye ${ }^{12}$, Nicholas O Frimpong ${ }^{13}$, Fred K Awittor ${ }^{2}$ and Iman K Martin ${ }^{14}$
}

\begin{abstract}
Background: Data on cancers is a challenge in most developing countries. Population-based cancer registries are also not common in developing countries despite the usefulness of such registries in informing cancer prevention and control programmes. The availability of population-based data on cancers in Africa varies across different countries. In Ghana, data and research on cancer have focussed on specific cancers and have been hospital-based with no reference population. The Kumasi Cancer Registry was established as the first population-based cancer registry in Ghana in 2012 to provide information on cancer cases seen in the city of Kumasi.

Methods: This paper reviews data from the Kumasi Cancer Registry for the year 2012. The reference geographic area for the registry is the city of Kumasi as designated by the 2010 Ghana Population and Housing Census. Data was from all clinical departments of the Komfo Anokye Teaching Hospital, Pathology Laboratory Results, Death Certificates and the Kumasi South Regional Hospital. Data was abstracted and entered into Canreg 5 database. Analysis was conducted using Canreg 5, Microsoft Excel and Epi Info Version 7.1.2.0.
\end{abstract}

Results: The majority of cancers were recorded among females accounting for $69.6 \%$ of all cases. The mean age at diagnosis for all cases was 51.6 years. Among males, the mean age at diagnosis was 48.4 compared with 53.0 years for females. The commonest cancers among males were cancers of the Liver (21.1\%), Prostate (13.2\%), Lung (5.3\%) and Stomach (5.3\%). Among females, the commonest cancers were cancers of the Breast (33.9\%), Cervix (29.4\%), Ovary (11.3\%) and Endometrium (4.5\%). Histology of the primary tumour was the basis of diagnosis in $74 \%$ of cases with clinical and other investigations accounting for $17 \%$ and $9 \%$ respectively. The estimated cancer incidence Age Adjusted Standardised Rate for males was 10.9/100,000 and 22.4/100, 000 for females.

Conclusion: This first attempt at population-based cancer registration in Ghana indicates that such registries are feasible in resource limited settings as ours. Strengthening Public Health Surveillance and establishing more Population-based Cancer Registries will help improve data quality and national efforts at cancer prevention and control in Ghana.

\section{Background}

Quality data on cancer in developing countries especially sub-Saharan Africa is a challenge for most countries [1]. Cancer registries, which are health units concerned with collecting systematically data on cancers, are useful sources of evidence on cancers. These centres when well established can provide high quality data on cancers as

\footnotetext{
* Correspondence: dlaryea@kathhsp.org

'Public Health Unit, Komfo Anokye Teaching Hospital, Kumasi, Ghana

${ }^{2}$ Kumasi Cancer Registry, c/o Public Health Unit, Komfo Anokye Teaching Hospital, Kumasi, Ghana

Full list of author information is available at the end of the article
}

has been advocated for [2] and are useful in planning cancer prevention and control activities [1]. Populationbased cancer registries (PBCR) are forms of cancer registries which provide information on cancers in a defined population. PBCRs are useful in estimating the incidence of cancer in specified populations. PBCRs are however not common in Africa and is highlighted by the poor representation of Africa in the global cancer estimates published by the World Health Organisation [3]. There are a handful of PBCRs in Africa with the African Cancer Registry Network (AFCRN) currently championing the cause for the establishment of more PBCRs in Africa 
[4]. Some nationally-based PBCRs exist in countries like The Gambia [5], city-based ones as the Ibadan and Abuja registries in Nigeria [6] or regional ones as the Eldoret Registry in Kenya [7].

Geographical location [8] or occupational settings [9] have been identified as risk factors for cancer in Ghana. Although smoking is not a significant public health issue in Ghana [10-12] unacceptably high levels of second hand smoking have been found in some places [9]. The recently passed Public Health Act outlaws smoking in public places and is seen as useful in reducing not only the incidence of second-hand smoking but smoking prevalence overall [13]. Human Herpes Virus 8 (HHV 8) associated with Kaposi Sarcoma has also been found to be highly prevalent in Ghana [14] as has Human Papilloma Virus (HPV) infections [15]. Despite the lack of population-based data on cancer in Ghana, there is some evidence of the public health importance of cancer in Ghana [16,17]. The need to develop a comprehensive programme on non-communicable disease control including cancers in Ghana has been highlighted $[18,19]$. Currently some activities with implications for cancer control and prevention are ongoing in Ghana. Hepatitis B vaccination is an integral part of Ghana's immunisation programme and may contribute to reducing the incidence of hepatitis B and possibly, liver cancer. Screening for specific cancers such as cervical cancer, although available, has been found to be low [18] while some attempts have also been made to introduce other methods of screening for some cancers hitherto not available in Ghana [20].

The burden of cancer in Ghana has not been static. Several studies on cancers in Ghana have focussed largely on cancers of specific sites [21-23] including the stages of presentation and have mainly been institutionally-based with no reference population $[16,17,24,25]$. There is the need for more comprehensive studies focussing on populations [26] in order to provide accurate information on cancers for action [2,27]. Some attempts have been made at collecting population-based cancer data in Ghana [28]. Cancer registration particularly population-based ones remain rare in Ghana. The Kumasi Cancer Registry was established in 2012 with the objective of providing population-based data on cancers in Kumasi. We set out to describe cancer cases seen in Kumasi and to estimate incidence using data from the Kumasi Cancer Registry in 2012.

\section{Methods}

This paper reviews data from the Kumasi Cancer Registry (KsCR) for 2012. The KsCR is a member of the AFCRN and started as a hospital-based cancer registry (HBCR) in 2004. It was converted to a PBCR in 2012 with the initial aim of providing data on cancers in the population of Kumasi and subsequently, the Ashanti Region of Ghana.
The reference geographic area for the registry is the city of Kumasi as designated by the 2010 Ghana Population and Housing Census.

We reviewed data collected from all clinical departments and the Pathology Department of the Komfo Anokye Teaching Hospital (KATH), Private Laboratory Results, and Death Certificates for 2012. We also reviewed cases recorded at the Kumasi South Regional Hospital. Other sources of data for cancer cases in Kumasi were Pathology Laboratory Reports, Biostatistics Index Cards, Out-patient Records and Haematology Laboratory Records. All cases of cancer were first identified and selected. Cases specific to Kumasi based on the place of usual residence were identified and selected for inclusion in our dataset. Required information including demographic, tumour and other clinical information were collected. Abstracted data was verified by a clinician before entry into CanReg 5 database. Further verification of data quality was conducted by the Registry Manager before confirmation into the database. The International Classification of Diseases for Oncology (ICD-O3) was used for classification and coding of cases of cancers recorded [29].

The incidence of multiple registrations was controlled by the use of multiple variables including the National Health Insurance Number, Date of Birth, Hospital ID number and Age of patient. This was necessitated by the lack of a single form of identification in Ghana. Names were not used as recommended [1] because of the similarity of names as well as variations in the spellings of some names.

Data was exported from Canreg 5 into Microsoft Excel $^{\odot}$ and analysed using Epi Info Version ${ }^{\odot}$ 7.1.2.0. Epi Info was used to generate means, frequencies and proportions. Microsoft Excel was used to generate charts and graphs. Canreg 5 was used to generate the crude and ASRs for the cases recorded.

Approval for the use of data from the Registry for the purpose of this publication was obtained from the Kumasi Cancer Registry Advisory Board. Ethical approval was from the Komfo Anokye Teaching Hospital/Kwame Nkrumah University of Science and Technology Committee on $\mathrm{Hu}$ man Research and Publication Ethics.

\section{Results}

The majority of cancers recorded for the period were among females and they accounted for $69.6 \%$ of all cases. The basic demographic information of cancer cases recorded in Kumasi for 2012 is as shown in Table 1.

The mean age (SD) at diagnosis for all cases was 51.6 (18.7) years with a median age of 53 years and a range of 1 to 90 years. Among males, the mean age (SD) at diagnosis was 48.4 (17.9) years, median age 48 years and a range of 1 to 90 years. Among females the mean age at 


\begin{tabular}{|c|c|c|}
\hline Parameter & Frequency & Percentage \\
\hline \multicolumn{3}{|l|}{ Sex } \\
\hline Male & 76 & 30.4 \\
\hline Female & 177 & 69.6 \\
\hline \multicolumn{3}{|l|}{ Age group } \\
\hline$<20$ & 15 & 5.9 \\
\hline $20-29$ & 15 & 5.9 \\
\hline $30-39$ & 27 & 10.7 \\
\hline $40-49$ & 52 & 20.6 \\
\hline $50-59$ & 53 & 20.9 \\
\hline $60-69$ & 42 & 16.6 \\
\hline 70-79 & 37 & 14.6 \\
\hline$>79$ & 12 & 4.7 \\
\hline \multicolumn{3}{|l|}{ Occupation } \\
\hline Trading & 97 & 38.3 \\
\hline Unemployed & 44 & 17.3 \\
\hline Farming & 27 & 10.7 \\
\hline Teaching & 11 & 4.4 \\
\hline Student & 10 & 4.0 \\
\hline Others & 64 & 25.3 \\
\hline
\end{tabular}

diagnosis was $53.0(18.8)$ years, median age 54 years and a range of 1 to 90 years.

The commonest sites for cancers reported among both sexes were Breast (24.1\%), Cervix Uteri (20.6\%), Ovary (7.9\%), Liver (6.4\%) and Prostate (4.0\%).

The most common cancers among males were cancers of the Liver (21.1\%), Prostate (13.2\%), Lung (5.3\%) and Stomach (5.3\%). Among females, the commonest cancers were cancers of the Breast (33.9\%), Cervix (29.4\%), Ovary (11.3\%) and Endometrium (4.5\%).

The histology of the primary tumour formed the basis of diagnosis in most $(73.71 \%)$ of cases. Figure 1 shows the basis of diagnosis for all cancers in this study.

Among cases histologically diagnosed, grading information was not available for 62 of the cases. For the 123 cases with tumour grading information available, moderately differentiated cases were the leading finding accounting for $49.6 \%$ of cases. The proportions for the various grades are as shown in Table 2 .

Based on the current population of Kumasi, the estimated crude cancer incidence for 2012 was 11.9 per 100,000 . Among males, the cancer incidence is 7.3/100,000 and 15.7/100,000 among females. The age-standardised incidence rates (ASR) for males was 10.9/100,000 and 22.4/100,000 for females. The ASR for the various tumour sites reported in Kumasi for 2012 is as shown

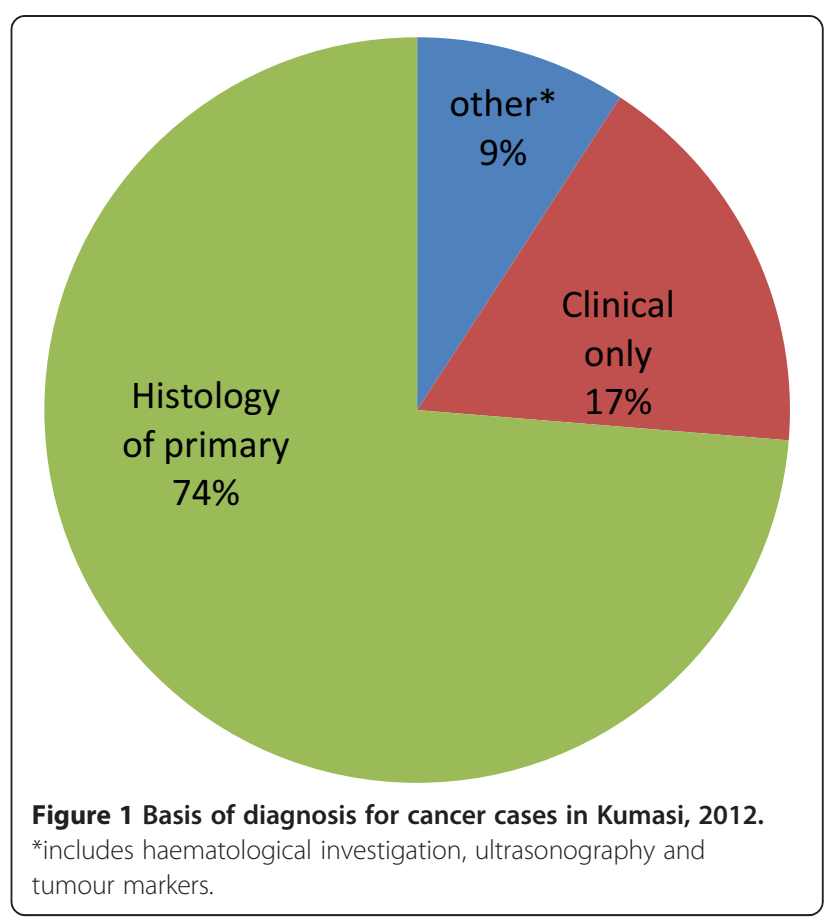

Tables 3 and 4. ASR by sex across all age groups is as shown in Figure 2.

\section{Discussion}

Our review of cancer in Kumasi is based on data collected with a reference population in mind in order to provide the basis for future estimation of the burden of cancers in Ghana and to assess the progress of cancer control programmes $[1,2,19]$. While a national PBCR may be ideal, the challenges to establishing such registries may include the lack of a uniform reporting system, the lack of a single national identification system, the multiple levels of independent healthcare delivery and the poor distribution of expertise in cancer diagnosis and treatment. Our use of multiple variables to reduce the incidence of multiple registrations is an example of actions that can be pursued to ensure that quality data is available for use in cancer prevention and control programmes.

Kumasi has largely been regarded as being conducive for the establishment of a PBCR because of the availability of laboratories and expertise to manage cancers. It

Table 2 Tumour types by grade

\begin{tabular}{lll}
\hline Grade & Frequency & Percentage \\
\hline Well differentiated & 17 & 13.8 \\
Moderately differentiated & 61 & 49.6 \\
Poorly differentiated & 35 & 28.5 \\
Undifferentiated & 10 & 8.1 \\
Total & 123 & 100.00 \\
\hline
\end{tabular}


Table 3 Frequency, age-specific incidence rates, average annual crude incidence rates, and ASR by site in females in Kumasi, 2012

\begin{tabular}{|c|c|c|c|c|c|c|c|c|c|c|c|c|c|c|c|c|c|c|c|}
\hline Site & All ages & $0-4$ & $5-9$ & $10-14$ & $15-19$ & $20-24$ & $25-29$ & $30-34$ & $35-39$ & $40-44$ & $45-49$ & $50-54$ & $55-59$ & $60-64$ & $65-69$ & $70-74$ & $75+$ & Crude rate & ASR \\
\hline Salivary glands & 2 & - & - & - & - & - & - & - & - & - & - & 2.5 & - & - & - & - & 3.9 & 0.2 & 0.2 \\
\hline Stomach & 1 & - & - & - & - & - & - & - & - & - & - & 2.5 & - & - & - & - & - & 0.1 & 0.1 \\
\hline Colon & 1 & - & - & - & - & - & - & - & - & - & - & - & - & - & - & - & 3.9 & 0.1 & 0.1 \\
\hline Anus & 1 & - & - & - & - & - & - & - & - & - & - & - & - & 4.5 & - & - & - & 0.1 & 0.2 \\
\hline Gall bladder & 1 & - & - & - & - & - & - & - & - & - & 2.3 & - & - & - & - & - & - & 0.1 & 0.1 \\
\hline Nose, Sinuses etc. & 2 & - & - & - & - & - & - & - & - & 1.8 & - & - & 4.2 & - & - & - & - & 0.2 & 0.3 \\
\hline Bone & 1 & - & - & 0.8 & - & - & - & - & - & - & - & - & - & - & - & - & - & 0.1 & 0.1 \\
\hline Melanoma of skin & 1 & - & - & - & - & - & - & - & - & - & 2.3 & - & - & - & - & - & - & 0.1 & 0.1 \\
\hline Other skin & 1 & - & - & - & - & - & - & - & - & - & - & - & - & 4.5 & - & - & - & 0.1 & 0.2 \\
\hline Kaposi Sarcoma & 1 & - & - & - & - & - & - & 1.5 & - & - & - & - & - & - & - & - & - & 0.1 & 0.1 \\
\hline Connective and soft tissue & 3 & - & 0.7 & - & 0.9 & - & - & 1.3 & - & - & - & - & - & - & - & - & - & 0.3 & 0.2 \\
\hline Breast & 59 & - & - & - & - & - & 2.0 & 5.1 & 7.6 & 10.9 & 21.1 & 20.4 & 29.7 & 31.2 & 29.7 & 22.3 & 11.6 & 5.3 & 7.9 \\
\hline Vulva & 2 & - & - & - & - & - & - & - & - & - & - & - & - & - & - & 5.6 & 3.9 & 0.2 & 0.2 \\
\hline Cervix uteri & 52 & - & - & - & - & - & - & 3.8 & 1.5 & 7.3 & 14.1 & 15.3 & 25.5 & 13.4 & 44.6 & 33.5 & 42.7 & 4.6 & 6.8 \\
\hline Corpus uteri & 8 & - & - & - & - & - & - & - & 1.5 & - & - & 5.1 & 4.2 & 4.5 & 7.4 & 11.2 & - & 0.7 & 1.1 \\
\hline Uterus unspecified & 1 & - & - & - & - & - & - & - & - & - & 2.3 & - & - & - & - & - & - & 0.1 & 0.1 \\
\hline Ovary & 20 & - & - & - & 0.9 & 1.8 & - & 1.3 & - & - & 2.3 & 10.2 & 12.7 & 8.9 & 14.9 & 11. & 7.8 & 1.8 & 2.6 \\
\hline Placenta & 3 & - & - & - & - & - & 1.0 & 1.3 & 1.5 & - & - & - & - & - & - & - & - & 0.3 & 0.2 \\
\hline Kidney & 2 & 1.3 & - & - & - & - & - & - & - & - & - & - & - & - & - & - & - & 0.2 & 0.2 \\
\hline Bladder & 2 & 2 & - & - & - & - & - & - & - & - & - & - & - & - & - & 5.6 & 3.9 & 0.2 & 0.2 \\
\hline Eye & 1 & - & - & - & 0.9 & - & - & - & - & - & - & - & - & - & - & - & - & 0.1 & 0.1 \\
\hline Brain, nervous system & 2 & - & - & - & - & & & & & & & & & & & & & & \\
\hline Non-Hodgkin lymphoma & 8 & 0.7 & 1.5 & 0.8 & - & 0.9 & - & - & - & 1.8 & - & 2.5 & - & - & - & - & 3.9 & 0.7 & 0.7 \\
\hline Multiple myeloma & 1 & - & - & - & - & - & - & - & - & - & - & - & - & - & - & - & 3.9 & 0.1 & 0.1 \\
\hline Other unspecified & 1 & - & - & - & - & - & - & - & - & - & - & - & 4.2 & - & - & - & - & 0.1 & 0.2 \\
\hline All Sites & 177 & 2.0 & 2.2 & 1.6 & 2.6 & 2.8 & 3.0 & 12.7 & 15.1 & 23.7 & 44.6 & 58.6 & 80.7 & 66.9 & 96.7 & 89.2 & 85.3 & 15.8 & 22.3 \\
\hline
\end{tabular}


Table 4 Frequency, age-specific incidence rates, average annual crude incidence rates, and ASR by site in males in Kumasi, 2012

\begin{tabular}{|c|c|c|c|c|c|c|c|c|c|c|c|c|c|c|c|c|c|c|c|}
\hline Site & All ages & $0-4$ & $5-9$ & $10-14$ & $15-19$ & $20-24$ & $25-29$ & $30-34$ & $35-39$ & $40-44$ & $45-49$ & $50-54$ & $55-59$ & $60-64$ & $65-69$ & $70-74$ & $75+$ & Crude rate & ASR \\
\hline Mouth & 1 & - & - & - & - & - & - & - & - & - & - & - & - & 5.1 & - & - & - & 0.1 & 0.2 \\
\hline Salivary glands & 2 & - & - & - & - & - & - & - & 1.7 & - & - & 3.0 & - & - & - & - & - & 0.2 & 0.3 \\
\hline Tonsil & 1 & - & - & - & - & - & - & - & - & - & - & - & 4.4 & - & - & - & - & 0.1 & 0.2 \\
\hline Oesophagus & 1 & - & - & - & - & - & - & - & - & - & 2.6 & - & - & - & - & - & - & 0.1 & 0.2 \\
\hline Stomach & 4 & - & - & - & - & - & - & - & - & - & 2.6 & 3.0 & 4.4 & 5.1 & - & - & - & 0.4 & 0.7 \\
\hline Colon & 1 & - & - & - & - & - & - & - & - & - & - & - & - & - & 8.9 & - & - & 0.1 & 0.3 \\
\hline Rectum & 1 & - & - & - & - & - & - & - & - & - & - & - & - & - & - & 8.1 & - & 0.1 & 0.2 \\
\hline Liver & 16 & 0.7 & - & - & - & 1.1 & 2.5 & 1.5 & - & 12.2 & 5.1 & - & - & - & 8.9 & 8.1 & 5.7 & 1.6 & 2.0 \\
\hline Gall bladder & 1 & - & - & - & - & - & - & - & - & - & 2.6 & - & - & - & - & - & - & 0.1 & 0.2 \\
\hline Larynx & 1 & - & - & - & - & - & - & - & - & - & - & - & 4.4 & - & - & - & - & 0.1 & 0.2 \\
\hline Trachea, bronchus and lungs & 3 & - & - & - & - & - & - & - & - & - & - & - & - & 15.4 & - & - & - & 0.3 & 0.6 \\
\hline Bone & 2 & - & - & - & - & 1.1 & - & - & - & - & 2.6 & - & - & - & - & - & - & 0.2 & 0.2 \\
\hline Other skin & 1 & - & - & - & - & - & 1.3 & - & - & - & - & - & - & - & - & - & - & 0.1 & 0.1 \\
\hline Mesothelioma & 1 & - & - & - & - & - & - & - & - & - & - & - & - & - & - & - & 5.7 & 0.1 & 0.1 \\
\hline Kaposi Sarcoma & 1 & - & - & - & - & - & - & - & - & - & - & 3.0 & - & - & - & - & - & 0.1 & 0.1 \\
\hline Connective and soft tissue & 4 & - & - & - & - & - & - & 3.0 & 1.7 & - & - & - & 4.4 & - & - & - & - & 0.4 & 0.5 \\
\hline Breast & 1 & - & - & - & - & - & - & - & - & - & 2.6 & - & - & - & - & - & - & 0.1 & 0.2 \\
\hline Prostate & 10 & - & - & - & - & - & - & - & - & - & - & - & - & 25.7 & - & 16.3 & 17.2 & 1.0 & 1.7 \\
\hline Testis & 1 & - & - & - & - & - & - & - & - & - & 2.6 & - & - & - & - & - & - & 0.1 & 0.2 \\
\hline Other male genital organs & 1 & - & - & - & - & - & - & - & - & 2.0 & - & - & - & - & - & - & - & 0.1 & 0.1 \\
\hline Kidney & 1 & - & 0.7 & - & - & - & - & - & - & - & - & - & - & - & - & - & - & 0.1 & 0.1 \\
\hline Bladder & 1 & - & - & - & - & - & - & - & - & - & - & - & - & - & 8.9 & - & - & 0.1 & 0.3 \\
\hline Brain, nervous system & 1 & - & - & 0.8 & - & - & - & - & - & - & - & - & - & - & - & - & - & 0.1 & 0.1 \\
\hline Thyroid & 1 & - & - & - & - & 1.1 & - & - & - & - & - & - & - & - & - & - & - & 0.1 & 0.1 \\
\hline Adrenal gland & 1 & - & - & - & - & - & - & 1.5 & - & - & - & - & - & - & - & - & - & 0.1 & 0.1 \\
\hline Hodgkin disease & 3 & - & - & 0.8 & - & - & - & - & - & - & 5.1 & - & - & - & - & - & - & 0.3 & 0.4 \\
\hline Non-Hodgkin lymphoma & 5 & - & - & - & - & - & 2.5 & - & - & - & - & 3.0 & - & 5.1 & - & 8.1 & - & 0.5 & 0.7 \\
\hline Lymphoid leukaemia & 1 & - & - & - & - & - & - & - & - & 2.0 & 2.6 & 3.0 & 8.9 & - & - & - & 5.7 & 0.1 & 0.1 \\
\hline Other unspecified & 8 & - & - & - & - & 1.1 & - & 1.5 & - & 2.0 & - & - & - & - & - & - & - & 0.8 & 1.1 \\
\hline All sites & 76 & 0.7 & 0.7 & 1.6 & - & 4.2 & 6.3 & 7.4 & 3.5 & 18.3 & 28.2 & 14.8 & 26.6 & 56.5 & 26.6 & 40.6 & 34.4 & 7.4 & 10.9 \\
\hline
\end{tabular}




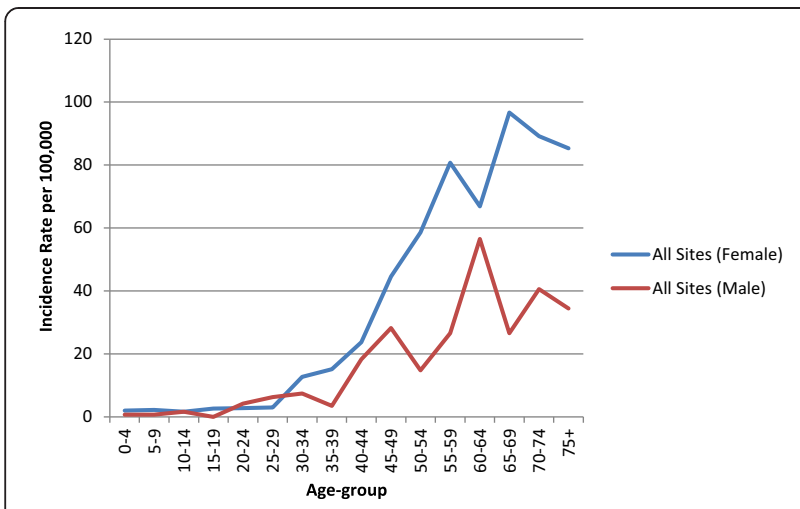

Figure 2 Age specific rates (ASR) for all cancers by sex in Kumasi, 2012.

also has fewer facilities offering oncology services allowing for cases to be easily identified and included in the registry database. Despite the challenges to cancer registration in developing countries $[1,28]$, our review of the first dataset from a PBCR in Ghana indicates that some of these challenges can be overcome and good quality population-based data obtained to inform planning and cancer control activities.

Cancer in Ghana has evolved over the last few decades. While this may not necessarily be indicative of changes in disease pattern, one of the commonest cancers recorded in the late 1950's was cancer of the Skin accounting for over a tenth of cancer cases recorded in Ghana [24]. Although skin cancers were rare in our dataset, we believe the observed high incidence in the late 1950s may be due to cases among white Ghanaian residents as Ghana was a British Colony at the time. Recent mortality reviews among cancer cases have shown lower rates of skin cancer-related mortality in Ghana [17].

The types of cancers recorded in Kumasi show some variation from studies on cancers in Ghana as well as other parts of Africa. There are also some consistencies observed. The high proportion of female cases is consistent with findings in the Gambia [5], Nigeria [30], Morocco [31] and from mortality records in Ghana [17]. Breast and cervical cancers were the leading cancers among females and this is also consistent with findings in other parts of Sub-Saharan Africa $[5,7,30]$ although much lower rates were recorded in Kumasi compared with Ibadan and Abuja in Nigeria [30]. Liver cancer was the leading cancer among males in our review and is consistent with findings in the Gambia [5]. Prostate cancer, although the second leading cause of cancers in Kumasi among males, accounted for a lower proportion compared with $28 \%$ in Abuja and 23\% in Ibadan [30]. Ovarian cancer as a proportion of female cancers was much higher in Kumasi (11.3\%) compared with Nigeria where a proportion of 3\% was recorded [30]. Lung cancers accounted for $1.6 \%$ for all cancers in our review and is consistent with findings in Nigeria (30) as Ghana and Nigeria share similar population characteristics. This may be due to the low prevalence of smoking [11,12] although the proportions are much lower compared with those recorded in other African countries as the Gambia (4\%), Morocco (19\%), [5,31].

\section{Limitations}

Our review is limited in terms of coverage by virtue of the fact that not all possible data sources in the Kumasi metropolitan area were included in the data collection. However, we estimate that the majority of cases of cancers in Kumasi are seen in KATH as it is the only hospital in the region with the requisite human resource and logistics to manage cancer cases. We are also likely to have missed cases among residents who may have sought treatment elsewhere outside the Kumasi city. This though may be difficult to ascertain as there currently exists no national database on cases of diseases seen in health facilities. It is unlikely that this will be solved in the near future as challenges exist at the national level on the quality of data. These may have accounted for the low incidence recorded. Our ranking of cancer cases (Table 5) show some consistency with those recorded by GLOBOCAN. However our estimates are low and may be due to some of the factors highlighted. Despite this, minimal variations are seen in the leading sites of tumours occurring among both sexes in Ghana. GLOBOCAN estimates the leading cancers in descending order as Liver, Prostate, Non-Hodgkin Lymphoma, Colorectum and Lip and Oral Cavity for males. Among females, the leading cancers were Cervix, Breast, Liver, Ovary and Non-Hodgkin Lymphoma [32]. In the absence of any form of population-based data on

\section{Table 5 Top ten sites of cancers recorded in Kumasi} (both sexes)

\begin{tabular}{lll}
\hline Site & Frequency & Percentage \\
\hline Breast & 61 & 24.1 \\
Cervix & 52 & 20.6 \\
Ovary & 20 & 7.9 \\
Liver & 16 & 6.3 \\
Prostate & 10 & 4.0 \\
Endometrium & 8 & 3.2 \\
Stomach & 5 & 2.0 \\
Lung & 4 & 1.6 \\
Kidney & 3 & 1.2 \\
Urinary bladder & 3 & 1.2 \\
Others & 71 & 28.1 \\
Total & 253 & 100.0 \\
\hline
\end{tabular}


cancers in Ghana, our data presents the best quality of population-based data yet, to be produced in Ghana.

We may also have underestimated the incidence of breast cancer in Kumasi as a private hospital in Kumasi was not included in our dataset because of administrative challenges. However, being the only tumour seen at this clinic, the exclusion of data from this site can only affect the overall incidence of cancer in Kumasi and breast cancers in particular but not the ranking of cases of cancers in Kumasi.

\section{Conclusion}

Population-based cancer registries are feasible in developing countries despite the challenges. Further strengthening of the cancer surveillance system in Kumasi in addition to the establishment of more PBCRs in Ghana is recommended in order to better estimate cancer incidence in Ghana and allow for evidence-based planning for cancer prevention and control.

\section{Abbreviations \\ PBCR: Population-based cancer registry; AFCRN: African Cancer Registry Network; KATH: Komfo Anokye Teaching Hospital; ASR: Age-standardised Incidence Rates; ICD-O3: International classification of diseases for oncology $3^{\text {rd }}$ edition; KSCR: Kumasi Cancer Registry; HPV: Human papilloma virus; HHV: Human herpes virus; HBCR: Hospital-based cancer registry.}

\section{Competing interests}

The authors declare no competing interests.

\section{Authors' contributions}

$D O L, Y A A, E O B$, IKM, and BA conceived and designed the study. DOL, YAA, $E O B, J D, N O F, R L-R, T O K, F K A, S B N, N A T, Y E, K O B, J O$ and DA were responsible for data collection and abstraction. DOL, FKA, IKM and BA were responsible for data management. DOL, FKA, and YAA performed the statistical analysis. DOL and YAA wrote the manuscript with contributions from all authors. All authors read and approved the final manuscript.

\section{Authors' information}

DOL is a Public Health Specialist and manages the Kumasi Cancer Registry. He holds a Membership in Public Health at the Ghana College of Physicians and Surgeons. He is also the Head of the Public Health Unit of KATH. BA is a Consultant Radiation Oncologist and Director of the KsCR. He serves on the KsCR Advisory Board. YAA is a Fellow of the West African College of Physicians. He is currently a Senior Specialist Physician at KATH and serves on the Advisory Board of the KsCR. EOB is a Radiation Oncologist and is currently the Head of the Oncology Department of the KATH. NOF is a Biostatistician and the former Head of the Biostatistics Unit of KATH. He serves as a member of the KsCR Advisory Board. JD is a Paediatric Oncologist and a Fellow of the West African College of Physicians. He is a Lecturer in Paediatrics at the Department of Child Health of the Kwame Nkrumah University of Science and Technology, Kumasi, Ghana. FKA is a Statistician and a Registrar with the Kumasi Cancer Registry. He also manages data collected for the KsCR. TOK is a Consultant Obstetrician Gynaecologist and a lead Gynaecological Oncologist at the Department of Obstetrics and Gynaecology, KATH. SBN is a Paediatrician and a Fellow of the West African College of Physicians. He serves on the KsCR Advisory Board. NAT is a Consultant Pathologist and the Head of the Pathology Department of KATH. $\mathrm{He}$ is also a member of the KsCR Advisory Board. He is also a Lecturer in Pathology at the KNUST School of Medical Sciences. KYA is a Public Health Specialist and the Metropolitan Director of Health of the Ghana Health Service, Kumasi. KOB is a Specialist Obstetrician Gynaecologist and Head of the Obstetrics and Gynaecology Department and the Clinical Coordinator of the Kumasi South Regional Hospital. He is also the Clinical Coordinator at the Kumasi South Regional Hospital. RL-R is a Senior Specialist ENT Surgeon and runs the Head and Neck Oncology Clinic with the Department of ENT, KATH. She also serves on the KATH's Head and Neck Tumour Board. DA is a Paediatrician and the Head of the Research and Development Unit of the Komfo Anokye Teaching hospital. He is also a Senior Lecturer in Paediatrics and the KbNUST School of Medical Sciences. JO is a Consultant General Surgeon and Lead Clinician of the Department of Surgery of the Komfo Anokye Teaching Hospital. IKM is a Fogarty Fellow with the University of Washington and has diverse experience on cancer registration in Sub-Saharan Africa.

\section{Acknowledgements}

The authors wish to acknowledge support staff of the Public Health and Biostatistics Units and the Department of Oncology of the Komfo Anokye Teaching Hospital. DOL received a travel and training grant from the AFCRN on Cancer Registration in 2012. IKM was funded by the Fogarty Global Health Fellowship to provide technical support for the Kumasi Cancer Registry.

\section{Author details}

${ }^{1}$ Public Health Unit, Komfo Anokye Teaching Hospital, Kumasi, Ghana. ${ }^{2}$ Kumasi Cancer Registry, c/o Public Health Unit, Komfo Anokye Teaching Hospital, Kumasi, Ghana. ${ }^{3}$ Department of Oncology, Komfo Anokye Teaching Hospital, Kumasi, Ghana. ${ }^{4}$ Department of Medicine, Komfo Anokye Teaching Hospital, Kumasi, Ghana. ${ }^{5}$ Department of Paediatrics, Komfo Anokye Teaching Hospital, Kumasi, Ghana. ${ }^{6}$ Department of Ear, Nose and Throat, Komfo Anokye Teaching Hospital, Kumasi, Ghana. ${ }^{7}$ Research and Development Unit, Komfo Anokye Teaching Hospital, Kumasi, Ghana. ${ }^{8}$ Metropolitan Directorate of Health Services, Ghana Health Service, Kumasi, Ghana. 'Department of Surgery, Komfo Anokye Teaching Hospital, Kumasi, Ghana. ${ }^{10}$ Department of Obstetrics and Gynaecology, Komfo Anokye Teaching Hospital, Kumasi, Ghana. ${ }^{11}$ Kumasi South Regional Hospital, Kumasi, Ghana. ${ }^{12}$ Department of Pathology, Komfo Anokye Teaching Hospital, Kumasi, Ghana. ${ }^{13}$ Biostatistics Unit, Komfo Anokye Teaching Hospital, Kumasi, Ghana. ${ }^{14}$ University of Washington, Northern Pacific Global Health Fellows, Kumasi, Ghana.

Received: 1 February 2014 Accepted: 20 May 2014 Published: 23 May 2014

\section{References}

1. Silva I dos S: Cancer Epidemiology: Principles and Methods. Lyon, France: International Agency for Research on Cancer; 1999.

2. Hanna TP, Kangolle AC: Cancer control in developing countries: using health data and health services research to measure and improve access, quality and efficiency. BMC Int Heal Hum Rights 2010, 10:24.

3. Curado M, Edwards B, Shin H, Storm H, Heanue M, Boyle P (Eds): Cancer Incidence in Five Continents. Lyon, France: International Agency for Research on Cancer; 2007.

4. Welcome to African Cancer Registry [Internet]. 2014. Available from: http://www.afcrn.org.

5. Bah E, Parkin DM, Hall AJ, Jack AD, Whittle H: Cancer in The Gambia: 1988-97. Br J Cancer 2001, 84(9):1207-1214.

6. Jedy-Agba EE, Curado M-P, Oga E, Samaila MO, Ezeome ER, Obiorah C, Erinomo OO, Ekanem IA, Uka C, Mayun A, Afolayan EA, Abiodun P, Olasode BJ, Omonisi A, Out T, Osinubi P, Dakum P, Adebamowo CA: The role of hospitalbased cancer registries in low and middle income countries - The nigerian case study. Cancer Epidemiol 2012, 36(5):430-435.

7. Tenge CN, Kuremu RT, Buziba NG, Patel K, Were PA: Burden and pattern of cancer in Western Kenya. East Afr Med J 2009, 86(1):7-10.

8. Armah FA, Gyeabour EK: Health risks to children and adults residing in riverine environments where surficial sediments contain metals generated by active gold mining in Ghana. Toxicol Res 2013, 29(1):69-79.

9. Agbenyikey W, Wellington E, Gyapong J, Travers MJ, Breysse PN, McCarty KM, Navas-Acien A: Secondhand tobacco smoke exposure in selected public places (PM2.5 and air nicotine) and non-smoking employees (hair nicotine) in Ghana. Tob Control 2011, 20(2):107-111.

10. Doku D, Darteh EKM, Kumi-Kyereme A: Socioeconomic inequalities in cigarette smoking among men: evidence from the 2003 and 2008 Ghana demographic and health surveys. Arch Public Heal 2013, 71(1):9.

11. Ghana Statistical Service: Macro International, Ghana Health Service. Ghana Demographic and Health Survey 2008. Accra: Ghana: GSS, GHS and ICF Macro; 2009. 
12. Owusu-Dabo E, Lewis S, McNeill A, Gilmore A, Britton J: Smoking uptake and prevalence in Ghana. Tob Control 2009, 18(5):365-370.

13. Parliament of the Republic of Ghana: Public Health Act. Accra: Parliament of the Republic of Ghana; 2012:851.

14. Adjei AA, Armah HB, Gbagbo F, Boamah I, Adu-Gyamfi C, Asare I: Seroprevalence of $\mathrm{HHV}-8, \mathrm{CMV}$, and EBV among the general population in Ghana. West Africa BMC Infect Dis 2008, 8:111.

15. Domfeh A, Wiredu E, Adjei A, Ayeh-Kumi P, Adiku T, Tettey Y, Gyasi RK, Armah HB: Cervical Human Papillomavirus Infection in Accra, Ghana. Ghana Med J 2008, 42(2):71-78.

16. Gyasi R, Tettey Y: Childhood Deaths from Malignant Neoplasms in Accra. Ghana Med J 2007, 41(2):78-81.

17. Wiredu EK, Armah HB: Cancer mortality patterns in Ghana: a 10-year review of autopsies and hospital mortality. BMC Public Health 2006, 6:159.

18. Adanu RMK, Seffah JD, Duda R, Darko R, Hill A, Anarfi J: Clinic Visits and Cervical Cancer Screening in Accra. Ghana Med J 2010, 44(2):59-63.

19. Bosu WK: A Comprehensive Review of the Policy and Programmatic Response to Chronic Non-Communicable Disease in Ghana. Ghana Med J 2012, 46(2 Suppl):69-78.

20. Awuah B, Martin IK, Takyi V, Kleer C, Nsiah-Asare A, Newman L: Implementation of a percutaneous core needle biopsy Training Program: Results from the University of Michigan-Komfo Anokye Teaching Hospital Breast Cancer Research Partnership. Ann Surg Oncol 2011, 18(4):957-960.

21. Clegg-Lamptey J, Hodasi W: A study of breast cancer in Korle Bu teaching hospital: Assessing the impact of health education. Ghana Med J 2007, 41(2):72-77.

22. Kitcher E, Yarney J, Gyasi R, Cheyuo C: Laryngeal Cancer at the Korle Bu Teaching Hospital Accra Ghana. Ghana Med J 2006, 40(2):45-49.

23. Ohene-Yeboah M, Adjei E: Breast Cancer in Kumasi, Ghana. Ghana Med 」 2012, 46(1):8-13

24. Wright JC: A Survey of Medical Conditions in Ghana in 1957. J Natl Med Assoc 1961, 53(4):313-320.

25. Yamoah K, Beecham K, Hegarty SE, Hyslop T, Showalter T, Yarney J: Early results of prostate cancer radiation therapy: an analysis with emphasis on research strategies to improve treatment delivery and outcomes. BMC Cancer 2013, 13:23.

26. Chu LW, Ritchey J, Devesa SS, Quraishi SM, Zhang H, Hsing AW: Prostate Cancer Incidence Rates in Africa. Prostate Cancer [Internet]. 2011. [cited 2013 Dec 3]; 2011. Available from: http://www.ncbi.nlm.nih.gov/pmc/ articles/PMC3200287/.

27. Graham A, Adeloye D, Grant L, Theodoratou E, Campbell H: Estimating the incidence of colorectal cancer in Sub-Saharan Africa: A systematic analysis. J Glob Heal 2012, 2(2). Available from: http://www.ncbi.nlm.nih. gov/pmc/articles/PMC3529315/.

28. O'Brien KS, Soliman AS, Awuah B, Jiggae E, Osei-Bonsu E, Quayson S, Adjei E, Thaivalappil SS, Abantanga F, Merajver SD: Establishing effective registration systems in resource-limited settings: cancer registration in kumasi, Ghana. J Regist Manag 2013, 40(2):70-77.

29. Fritz A, Percy C, Jack A, Shanmugaratnam K, Sobin L, Parkin DM, Whelan S (Eds): International Classification of Diseases for Oncology. Geneva, Switzerland: World Health Organisation; 2000.

30. Jedy-Agba E, Curado MP, Ogunbiyi O, Oga E, Fabowale T, Igbinoba F, Osubor G, Otu T, Kumai H, Koechlin A, Osinubi P, Dakuma P, Blattner W, Adebamawo CA: Cancer Incidence in Nigeria: A Report from Populationbased Cancer Registries. Cancer Epidemiol 2012, 36(5):e271-e278.

31. Tazi MA, Er-Raki A, Benjaafar N: Cancer incidence in Rabat, Morocco: 2006-2008. Ecancermedicalscience; 2013. Aug 8 [cited 2013 Dec 4]; 7. Available from: http://www.ncbi.nlm.nih.gov/pmc/articles/PMC3737118/.

32. Fact Sheets by Population [Internet]. 2014. Available from: http://globocan. iarc.fr/Pages/fact_sheets_population.aspx.

doi:10.1186/1471-2407-14-362

Cite this article as: Laryea et al:: Cancer incidence in Ghana, 2012: evidence from a population-based cancer registry. BMC Cancer 2014 14:362.

\section{Submit your next manuscript to BioMed Central and take full advantage of:}

- Convenient online submission

- Thorough peer review

- No space constraints or color figure charges

- Immediate publication on acceptance

- Inclusion in PubMed, CAS, Scopus and Google Scholar

- Research which is freely available for redistribution 